\title{
Study on Long-term Water Quality Protection Mechanism Framework of Inter-basin Water Diversion Protect
}

\author{
YIN Xiaolin \\ (China Institute of Water Resources and Hydropower Research, Beijing 100048, China)
}

\begin{abstract}
With the increasing and complicated contradiction between the supply and demand of water resources in recent years, a number of inter-basin water diversion projects have been built in various places in China. The water supply objects of the inter-basin water diversion projects are mostly industrial and domestic water, and the water quality is closely related to the success or failure of the water transfer project, which makes it necessary to establish a long-term water quality protection mechanism. On the basis of analyzing major issues in water quality protection in inter-basin water transfer projects, a long-term mechanism framework for water quality protection was established and elaborated from the aspects of institutional system, water quality goals, risk management, guarantee conditions, feedback mechanism, technical evaluation, administrative assessment, public participation, incentive measures, aiming to provides reference for the water quality safety inter-basin water diversion projects.
\end{abstract}

\section{Introduction}

The inter-basin water transfer project is a strategic infrastructure for solving regional water resources shortage and an important means for optimal allocation of water resources. In order to solve the water resources demand for economic and social development, since the founding of New China, China has successively planned and launched a large number of inter-basin and interregional water transfer projects of different types and sizes. These projects have exerted significant economic, social and ecological benefits, and have supported and guaranteed regional economic and social development and regional ecological environment improvement. According to incomplete statistics, there are nearly 70 important water transfer projects in China, including 7 large-scale inter-basin water transfer projects and nearly 62 major regional water transfer projects, covering 26 provinces. Among the nearly 70 water transfer projects, 32 have been built, 23 are under construction, and 14 are in the early stage of work. In addition, according to the national comprehensive water resources plan, by 2030, China still needs to increase 112.8 billion cubic meters of water supply, of which more than $60 \%$ will be realized through inter-basin water transfer.

With the acceleration of urbanization and the development of industry, urban and ecological water shortage have gradually become prominent. The target of water transfer project has shifted from agricultural irrigation to domestic and industrial water supply. Life and industry have high requirements for water quantity and quality, which requires the water quality to always remain stable. It can be said that the water quality determines the success or failure of the water transfer project. The interbasin water transfer project has a long line and involves many interest groups, and water quality protection work for each project is a systematic, long-term and regular work. To ensure the long-term stability of water quality, it is necessary to establish a long-term mechanism framework for water quality protection from various aspects such as laws and regulations, institutional mechanisms, policy support, and supervision and management.

\section{Major issues in water quality protection in inter-basin water transfer projects}

Through the analysis of the operation and management practice of the current water transfer project, the problems faced by the water quality protection work can be mainly classified into the following aspects:

(1) High water quality requirements, task of water quality protection is arduous

The water supply targets for inter-basin water transfer projects generally include domestic, industrial, irrigation, and ecological water use. With the economic and social development and urbanization, the water transfer projects for urban life and industrial water supply are increasing. Typical characteristics of urban and industrial water use are high water supply guarantee rates and high water quality requirements. This requires that the water transfer project attach great importance to water quality protection work. In the project planning stage, it is necessary to make overall arrangements for the project water quality protection project, water quality objectives, water quality 
protection system and so on, and formulate and implement water quality protection plan. In the project operation stage, it is necessary to further improve the water quality protection working mechanism and laws and regulations, and mobilize relevant forces to participate in water quality protection work to ensure the good water quality and achieve a benign operation of the project.

(2) Involving multiple stakeholders, communication and coordination is difficult

Inter-basin water transfer projects generally involve multi-faceted interests, including water source areas, water receiving areas, different watersheds, different provinces, and different water industries. The construction and operation management of inter-basin water transfer projects is a complex giant system, and it is also a process of redistribution of interests. In order gain a good water quality, the water source area and the areas along the project have to adjust the industrial structure, limit the development of high-pollution industries, and lose some development opportunities for water quality protection work. Due to the consideration of their own interests, the parties may be difficult to make concessions on related issues in water quality protection, resulting in difficulties in communication and coordination.

(3) Long project trunk line and numerous water quality risk factors

The inter-basin water transfer project generally has a long line, and there are many factors affecting water quality. There are multiple water quality risk factors in water source areas, reservoirs, reservoirs, and areas along the project. Once an accident occurs in the upstream channel connected to water transfer project, the sewage may flow into the water transfer project trunk line and a water quality risk accident will occur. In addition, with the further development of industry and agriculture along the line, pollutants such as non-point source pollution, rural sewage, and animal husbandry aquaculture wastewater may increase further, which constitute a potential risk source for water quality protection. The water quality risk factors of the water transfer project include: sudden water pollution incidents, production and domestic sewage discharge, ship pollutant discharge, artificial poisoning risk, long-term operation of sediment and algae pollution risk and so on (Seen in Figure 1).

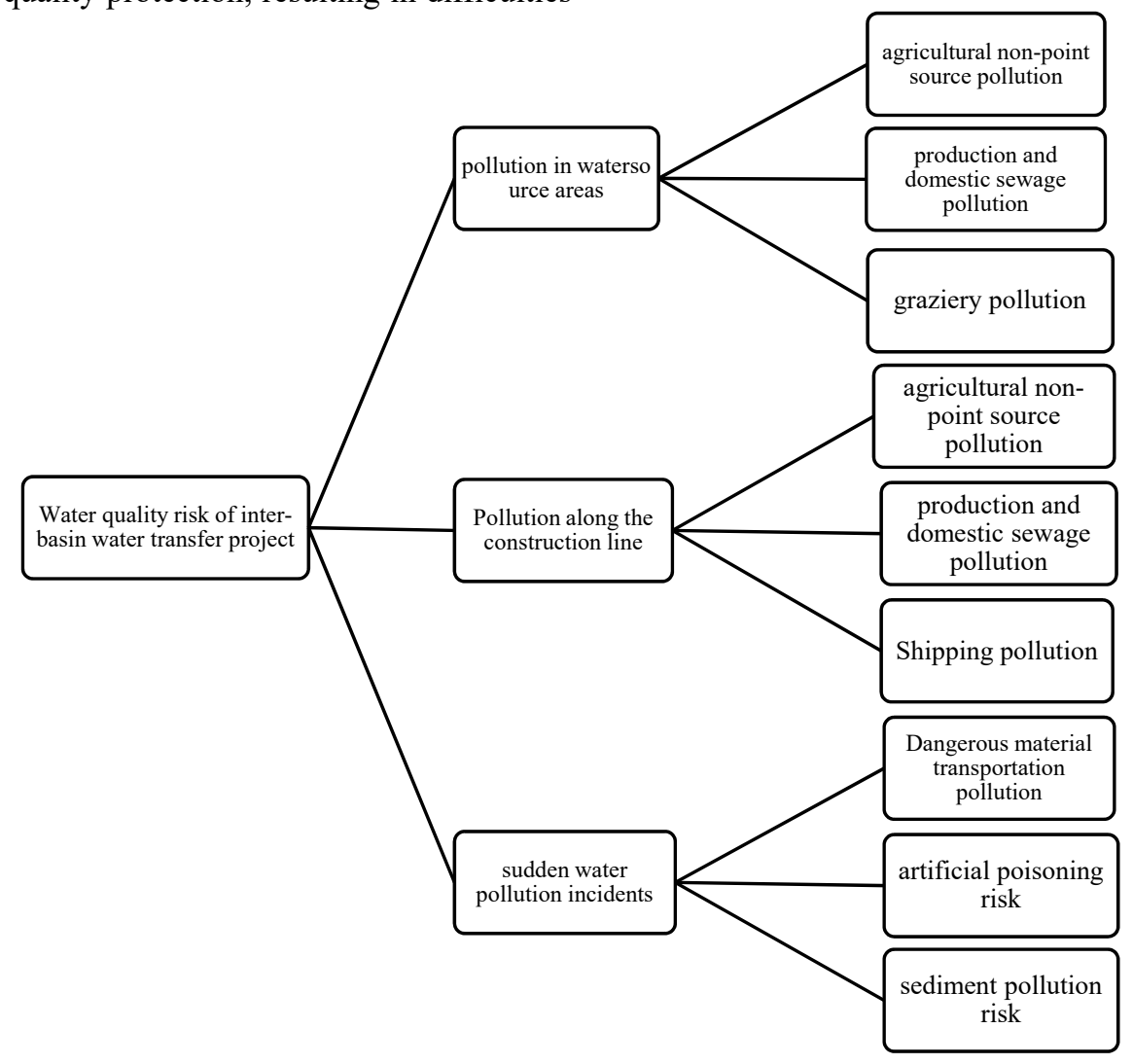

(4) In the event of a water pollution incident, the loss and impact are serious

Once a water pollution incident occurs in an interbasin water transfer project, its losses and impacts are large. On the one hand, the operation and management of the water transfer project is complicated. Once the water pollution incident occurs, the scheduling and operation of the whole project must be adjusted accordingly. On the other hand, many areas with severe water shortage in the water receiving area are highly dependent on the water of transfer project, due to that the water of the water transfer project has been changed from the original planned supplementary water source to the conventional water source. Once the water quality deteriorates, the inter-basin water transfer project will not be able to supply water properly, and the economic and social impacts of these places will be severe. 


\section{Long-term mechanism framework for water quality protection in inter-basin water transfer projects}

A long-term mechanism is a system which could guarantee a job done properly and performed well. The long-term mechanism is not a separate system or several isolated systems. It should be a systematic system composed of multiple aspects. It has several key factors. Firstly, it is necessary to build a relatively standardized, stable, and supportive system. Secondly, a "power source" is needed, including organizations and individuals which could actively promote and supervise the operation of the system for their own interests or for performing their duties. Third, there is an efficient feedback mechanism to promote the continuous improvement of water quality protection work. Fourthly, it can adjust and improve the feedback results and revealed problems.

\subsection{Design Principles}

Considering the arduousness, systemicity and integrity of the water quality protection work of the inter-basin water transfer project, the design of its long-term mechanism framework should embody the following principles:

Coordinate the interests of all parties concerned and take into account the protection of water resources development and utilization. The water quality protection of water transfer project generally involves the adjustment of industrial structure in the water source area, the pollution control of production, living and shipping vessels etc., which may have a greater impact on the economic and social development and living habits of the residents along the project trunk line. The long-term mechanism should include incentives and compensation mechanisms that can fully reflect fairness and justice, to avoid efficiency moving from one place to another. While ensuring the safety of water quality, measures should be taken to stimulate the willingness of social forces to participate in water quality protection work, and realize the dialectical unity of ecological environment development.

Adhere to the local conditions and highlight key points. The long-term mechanism should be based on the existing achievements and established systems of pollution control and environmental protection work in inter-basin water transfer projects. According to the natural conditions and economic development conditions along the cross-domain areas of the project, the water should be transferred based on water conservation, and be the pollution should be control well before water passing the trunk line. Through the standardized system design and scientific measures, the goal of long-term mechanism of water quality protection and the specific measures could be unified.

Rationalize the relationship between rights and obligations. Under the clear system of operation and management of water transfer projects, rationalize the rights and obligations between the central and local departments of the project, different departments, and propose reasonable division of responsibilities. The duties and responsibilities of each management unit are not only parallel but also organically combined to avoid the ills of the fragmentation that may occur in multi-party management. The macro-design of the long-term mechanism for pollution control and environmental protection must be implemented into specific institutional measures. This requires the system to form a closed, related, and scientific system. Each part of the system has a clear division of labor and coordination.

\subsection{Long-term mechanism framework design for water quality protection}

Based on the current operation and management of interbasin water transfer projects in China, this study proposes that the long-term mechanism framework for water quality protection involves management systems, policy measures, technical inputs, and public relations. Specifically, it can include nine aspects: institutional system, water quality objectives, safeguard conditions, public participation, pollution risk management, analysis and evaluation, supervision and assessment, incentive measures and feedback mechanisms.

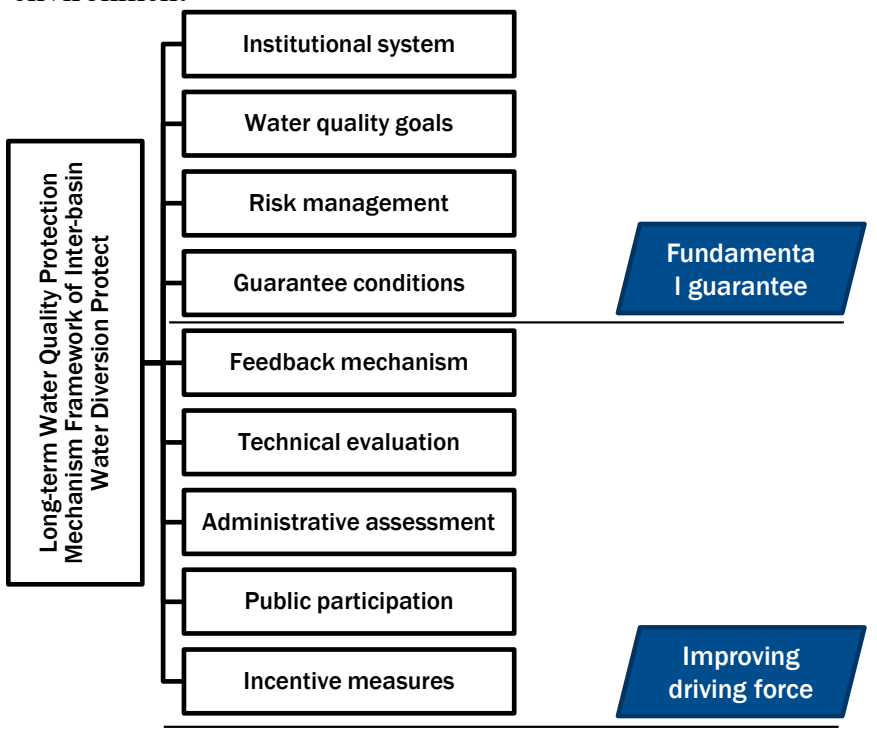


(1) Institutional system

The institutional system is the basic follow-up of the water quality protection work of the inter-basin water transfer project. It can provide basic institutional basis and support for the implementation of water quality protection work. The comprehensive scientific system is the core content of the long-term mechanism of water quality protection. The water quality protection system of the water transfer project should include water quality monitoring system, water quality protection consultation system, information exchange and sharing system, performance appraisal system, public participation and social supervision system, water quality dispute resolution system, etc.

(2) Water quality goals

The inter-basin water transfer project has clear water supply targets, and the water supply targets are generally urban and industrial water, which requires high water quality. The water quality protection work of the water transfer project must have clear water quality protection goals. The scientific and reasonable water quality goal is the ultimate aim of water quality protection work. All work needs to be carried out around this goal. For example, in the water quality protection work of the South-to-North Water Diversion Project, the water quality of the project should be maintained in Class II or better than Class II. The water quality of the project has been stable since the project was passed though, which has guaranteed the drinking water safety of the people in the north and changed the water supply pattern of the northern water receiving area. The degree of water supply assurance has been greatly improved, and the water quality and drinking taste have been greatly improved.

(3) Risk management

There are many water quality risk factors for interbasin water transfer projects. Some of the project water transfer trunks are connected with the natural water surface, which make it is impossible to implement closed protection and increase the difficulty of coordinating and coordinating multi-sector pollution control. Therefore, it is necessary to strengthen the management of water quality risk sources along the inter-basin water transfer project. Firstly, it should conduct a comprehensive and systematic analysis of the water quality risk factors faced by the project operation management, screen the main water quality risk factors, formulate the water pollution incident emergency plan, which should include the emergency work disposal method, organization leadership, work procedures, technical and financial support, etc.

(4) Guarantee conditions

Technology and investment are important foundations for achieving long-term stability of water quality in water transfer projects. In the daily water quality protection of the project and the occurrence of water pollution incidents, the corresponding technical, financial and human resources are required. The protection in daily water quality protection is mainly the input required for the construction of pollution control and environmental protection projects, such as industrial structure adjustment, industrial comprehensive treatment, urban sewage treatment and recycling, comprehensive improvement of watershed and interception and sewage control. For example, the first phase of the East Route of the South-toNorth Water Diversion Project has invested a total of 17.4 billion Yuan since the implementation of the Pollution Control Plan for the East Route of the South-to-North Water Diversion Project. In 2012, the chemical oxygen demand of major pollutants and the total amount of ammonia nitrogen into the river decreased by more than $85 \%$ compared with the planned 2000 years, effectively ensuring the stable performance of the project benefits.

(5) Feedback mechanism

Information feedback is an important part of the water quality protection work of the inter-basin water transfer project. It can promote the long-term improvement and gradual improvement of water quality protection work. The feedback mechanism mainly includes feedback on water quality monitoring, feedback on implementation of policy measures, and feedback on decision support. Water quality monitoring feedback includes mainline water quality monitoring, tail water quality monitoring, sewage quality monitoring, and lake water quality monitoring. The feedback on the implementation of policy measures is a combing analysis of the implementation, implementation effects, and existing problems of specific measures such as water quality protection policies, plans, programs, and projects, and proposes solutions to problems to achieve self-improvement of pollution control and environmental protection policies and measures. Decision support information feedback refers to the use of information technology to collect, store and organize data related to water quality protection, and provide information support for relevant departments in decisionmaking such as water resources protection, water pollution control, flood control and drought relief, and engineering planning.

(6) Technical evaluation

In order to understand the water quality protection effect of the inter-basin water transfer project in a timely manner, a water quality protection effect tracking and evaluation system should be established, and the evaluation work should be normalized, institutionalized and standardized. The technical evaluation work should firstly formulate a work plan, to standardize the evaluation methods, evaluation indicators, evaluation frequency, evaluation content, and use of evaluation results. Generally speaking, the evaluation content should include: the establishment of water quality protection work management system and working mechanism, the formulation and implementation of relevant laws and regulations system, water quality protection planning and project implementation and operation, emergency response preparation and so on.

(7) Administrative assessment

On the basis of technical evaluation, in order to further promote the implementation and rectification of problems found in the technical assessment, an administrative assessment work mechanism and assessment plan for water quality protection work should be established to conduct an administrative assessment of the water quality protection work of the inter-basin water transfer project. The water quality will be as a binding indicator and be included in the assessment system of the party committee 
and government leading bodies, and cadres at all levels and the county economic and social development assessment system, which forms a powerful mechanism for local water quality protection.

(8) Public participation

At present, the experience of the occurrence and disposal of major water pollution incidents in China shows that the current social forces have become important participants in the pollution control and environmental protection work of large-scale water source projects. The active participation of the public could make up for the lack of monitoring capabilities of existing monitoring facilities. For the water quality protection work of water transfer projects, the narrow public participation refers to the use of people along the line to assist in the supervision and monitoring of water quality protection, environmental protection, soil and water conservation, etc. The employees in the agriculture, fishery and shipping industries around the project could conscientiously implement the relevant regulations on pollution control and environmental protection. The broad public participation refers to the national media and the public's attention to the water quality protection work of the water transfer project and the participation of the participants, including the right to information, supervision and participation.

\section{(9) Incentive measures}

The implementation of pollution control and environmental protection measures and the adjustment of industrial structure in the water quality protection of interbasin water transfer projects have increased the pollution control costs of industrial and mining enterprises along the project, especially in the water source areas. Starting from the goal of long-term safety and stability of water quality, a set of incentive system with clear rewards and punishments should be established. Certain policy inclinations or economic incentives will be given to areas that are seriously implementing pollution control measures and good water quality in the country, which will help to form a good atmosphere for pollution control, and encourage local governments along the project to continue to pay more attention to pollution control.

\section{Conclusion}

In view of the major issues faced by water quality protection in inter-basin water transfer projects, this study proposes a long-term mechanism framework for water quality protection of water transfer projects, including institutional system, water quality goals, risk management, guarantee conditions, feedback mechanism, technical evaluation, administrative assessment, public participation, incentive measures. The purpose is to form an authoritative and synergistic force for water quality protection among all parties involved in the inter-basin water transfer project, relying on the joint efforts of local governments and their functional departments along the project to ensure and guide the multi-level stakeholders of the society to participate in water quality protection work. It is of certain guiding significance and practical value to smoothly promote the water quality protection of the inter- basin water transfer project and realize the stable performance of the trans-basin water transfer project.

\section{References:}

1. LIU Chang-ming, HE Xi-wu. Strategy on water resources issues in Century 21 of China [M]. Science Press, Beijing, 1996. (in Chinese)

2. CHEN Zhi-kai. The Issues of Sustainable Utilization of Water Resources in China[J]. Hydrology, 2003,23(1):1-5. (in Chinese)

3. Bureau of South - to - North Water transfer of planning, designing and management, ministry of water resources. General programming of South - to North Water Diversion Project [M]. 2002. (in Chinese)

4. XU Xin-yi. Reasonable allocation of water of the south-to-north water transfer project is the general planning of theoretical basis $[\mathrm{J}]$. China Water Resources, 2001,8:22-24. (in Chinese)

5. GUO Xiao,FANG Guo-hua,ZHANG Zhe-kai. Study on the indicator system of inter-basin water transfer ecological environment impact assessment[J]. Journal of Hydraulic Engineering, 2008(09):11251130. (in Chinese)

6. GAO Yong-nian, GAO Jun-feng. Comprehensive evaluation of the impact of the middle route of southto-north water transfer project on the ecological environment of the middle and lower reaches of the han river basin[J]. Progress in Geography,2010,29(1):59-64. (in Chinese)

7. CHEN Jin, HUANG Wei. Risk and countermeasures of interbasin long-distance water diversion project[J]. China's water conservancy,2006(14)11-14. (in Chinese)

8. ZHU Jiu-long. Domestic and foreign studies on ecological compensation for interbasin water transfer source area [J]. Yellow River,2014(02)78-81. (in Chinese)

9. WANG Ming-na,WANG Da. Comprehensive analysis of the environmental impact of water diversion project[J]. Water Resources Protection,2002(04):10-14. (in Chinese)

10. DOU Ming, ZUO Qi-ting, HU Cai-hong. Ecological environmental impact assessment of the south-tonorth water diversion project[J]. Journal of Zhengzhou University ( Engineering Science ) [J],2005(02)63-66. (in Chinese)

11. ZHANG Jian-yun, CHEN Jie-yun. Study on the eastern route of south-to-north water transfer project[J],1995,6(3):198-204.(02)63-66.

12. WANG Jin-feng, LIU Chang-ming, YU Jie-jing. Study on spatial and temporal optimal allocation model of interregional water transfer[J]. Journal of Hydraulic Engineering,2001,32 (4): 7-14). (in Chinese) 